Federal Reserve Bank of Minneapolis

Research Department Staff Report 166

December 1993

\title{
Household Production and Taxation in the Stochastic Growth Model
}

\author{
Ellen McGrattan*
}

Federal Reserve Bank of Minneapolis

\author{
Richard Rogerson* \\ University of Minnesota and \\ Federal Reserve Bank of Minneapolis
}

\author{
Randall Wright* \\ University of Pennsylvania and \\ Federal Reserve Bank of Minneapolis
}

\begin{abstract}
We estimate a dynamic general equilibrium model of the U.S. economy that includes an explicit household production sector. We use these estimates to investigate two issues. First, we analyze how well the model accounts for aggregate fluctuations. Second, we use the model to study the effects of fiscal policy. We find household production has a significant impact, and reject a nested specification in which changes in the home production technology do not matter for market variables. The model generates very different predictions for the effects of tax changes than similar models without home production.
\end{abstract}

*We thank participants in workshops at Cornell, the Federal Reserve Bank of Atlanta, Georgetown, North Carolina State, Northwestern, Queens, and Virginia for their input, and the National Science Foundation for its financial support. The views expressed herein are those of the authors and not necessarily those of the Federal Reserve Bank of Minneapolis or the Federal Reserve System. 


\section{Introduction}

In this paper, we estimate a dynamic general equilibrium model of the U.S. economy that includes an explicit household production sector. We use our estimates to investigate two issues. First, we analyze how well the model accounts for aggregate fluctuations. Second, we use the model to study the effects of tax changes.

There are several reasons why the inclusion of a household sector may be important for these issues. For one thing, home production is a large part of economic activity. ${ }^{1}$ More importantly, the addition of household production influences the ability and willingness of individuals in a model to substitute into and out of market activity. We expect, therefore, that models with home production will have different predictions concerning the way in which the economy reacts to changes in economic conditions, both in the short run and in the long run, and hence different implications for business cycles and fiscal policy.

Becker (1988) argues that home production may be important for these types of macroeconomic questions. Benhabib, Rogerson, and Wright (1991) and Greenwood and Hercowitz (1991) show that adding home production can improve the quantitative performance of real business cycle models along several dimensions. Rios-Rull (1993) argues that home production is an important element in explaining cross section and life cycle patterns in wages and employment. Unfortunately, however, the extent to which home production matters in these models depends critically on the elasticities of substitution between household and market variables in utility and production functions. The same parameters are likely to be important for fiscal policy; for example, it is well-known in the growth literature that the effects of tax changes hinge on similar elasticities (see Stokey and Rebelo 1993).

In previous studies, these parameters have been set more or less arbitrarily. We obtain maximum likelihood estimates of our model using postwar U.S. time series. ${ }^{2}$ Our estimates

1 As reported in Greenwood, Rogerson, and Wright (1993), a typical family spends almost as much time in home production activities, such as cooking, cleaning, child care, and so on, as it does working for paid compensation ( 25 percent of discretionary time versus 33 percent of discretionary time). And there is actually more investment in household capital, defined as residential structures and consumer durables, than there is in business capital, defined as plant and equipment.

2 Previous attempts to estimate related models using maximum likelihood methods include Christiano (1988), Altug (1989), and McGrattan (1992), but none of these papers included home production, 
imply that agents have significant incentives and willingness to substitute between the market and household sectors, and this implies household production has a significant effect on business cycles. In particular, we reject a nested specification in which changes in the home production technology do not matter for market variables. Overall, the model is similar to previous real business cycle models in matching the set of moments on which real business cycle theorists like to concentrate. Furthermore, our estimates for preference and technology parameters are not sensitive to transforming the data by removing low frequencies before estimation.

We consider several fiscal policy experiments: eliminating the capital income tax and making up the lost revenue by increasing the labor income tax; eliminating all distortionary taxation; and changing the tax rate on nonmarket capital. The model generates very different predictions as compared to similar models without home production, such as the one in McGrattan (1992). For example, if we reduce the capital income tax rate from its sample mean to zero, our model predicts that the labor income tax rate would have to rise from its sample mean of 23 percent to 31 percent to make up the revenue loss. This policy increases output by 14 percent and increases welfare by an amount equivalent to 10.6 percent of market consumption. In comparison, the model without home production implies the labor income tax rate would have to rise to 36.5 percent, output increases by 21 percent, and welfare increases by an amount equivalent to 14.7 percent of market consumption.

The rest of the paper is organized as follows. In Section II we present the model and define equilibrium. In Section III we describe the estimation procedure and data. In Section IV we discuss the empirical results. In Section $\mathrm{V}$ we focus on business cycle implications, and in Section VI we analyze the fiscal policy experiments. Section VII contains some brief summary remarks.

\section{The Model}

Consider a discrete time stochastic growth model, with a continuum of infinite-lived, homogeneous individuals whose total population is normalized to unity. They have pref-

and only McGrattan (1992) considered taxes. 
erences over stochastic processes for consumption $c_{t}$ and leisure $\ell_{t}$ described by the utility function

$$
\mathcal{U}=E_{0} \sum_{t=0}^{\infty} \tilde{\beta}^{t} u\left(c_{t}, \ell_{t}\right)
$$

where $E_{0}$ is the expectation operator conditional on information available at date 0 , and $\tilde{\beta}$ is the discount factor. We take momentary utility to be a constant relative risk aversion transformation of a Cobb-Douglas function,

$$
u\left(c_{t}, \ell_{t}\right)=\frac{\left(c_{t}^{b} \ell_{t}^{1-b}\right)^{1-\sigma}-1}{1-\sigma} .
$$

Consumption and leisure in our model are aggregates of other variables. Leisure is given by

$$
\ell_{t}=\bar{h}-h_{m t}-h_{n t}
$$

where $\bar{h}$ is total discretionary time, $h_{m t}$ is hours of market work, and $h_{n t}$ is hours of nonmarket (home) work. Consumption is an aggregate of private consumption $c_{p t}$ and government consumption $c_{g t}$ :

$$
c_{t}=\left\{a_{1} c_{p t}^{b_{1}}+\left(1-a_{1}\right) c_{g t}^{b_{1}}\right\}^{\frac{1}{b_{1}}}
$$

Private consumption itself is an aggregate of market consumption $c_{m t}$ and nonmarket consumption $c_{n t}$ :

$$
c_{p t}=\left\{a_{2} c_{m t}^{b_{2}}+\left(1-a_{2}\right) c_{n t}^{b_{2}}\right\}^{\frac{1}{b_{2}}} .
$$

For convenience below, we combine (2.2)-(2.5) to write momentary utility as

$$
u\left(c_{t}, \ell_{t}\right)=U\left(c_{m t}, c_{n t}, c_{g t}, h_{m t}, h_{n t}\right) .
$$

The household maximizes utility subject to several constraints. First, it owns capital $k_{t}$, that it can divide at a point in time between market capital $k_{m t}$ and nonmarket capital $k_{n t}$,

$$
k_{t}=k_{m t}+k_{n t} .
$$

The household combines nonmarket capital with hours to produce the nonmarket good, according to the home production function

$$
c_{n t}=\left\{a_{3} k_{n t}^{b_{3}}+\left(1-a_{3}\right)\left(\mu^{t} e^{s_{n t}} h_{n t}\right)^{b_{3}}\right\}^{\frac{1}{b_{3}}},
$$


where $\mu$ is a trend growth rate and $s_{m t}$ is a stochastic shock, both of which are labor augmenting. Constraint (2.8) says that home consumption must be produced in the home (that is, it cannot be bought or sold on the market).

The household's capital stock evolves according to the law of motion

$$
k_{t+1}=(1-\tilde{\delta}) k_{t}+i_{t}
$$

where $i_{t}$ denotes investment and $\tilde{\delta}$ depreciation. Capital that is not used in home production is rented to firms in the market. The market variables are constrained according to a standard budget equation

$$
c_{m t}+i_{t} \leq\left(1-\tau_{h t}\right) w_{t} h_{m t}+\left(1-\tau_{k t}\right) r_{t} k_{m t}+\tilde{\delta} \tau_{k t} k_{m t}+T_{t}
$$

where $w_{t}$ and $r_{t}$ are the real wage rate and rental rate on capital, $\tau_{h t}$ and $\tau_{k t}$ are (stochastic) taxes on labor and capital income, and $T_{t}$ is a lump sum transfer. Note that depreciation is tax deductible, and that the household has no dividend income (since profits will be zero in equilibrium). Also note that we can always decompose $i_{t}$ into market plus nonmarket investment, $i_{t}=i_{m t}+i_{n t}$, where $i_{s t}=k_{s t+1}-k_{s t}(1-\tilde{\delta})$ for each sector $s .^{3}$

Taxes in the model are determined by a fiscal authority that faces a budget constraint,

$$
c_{g t}=H_{m t} w_{t} \tau_{h t}+K_{m t} r_{t} \tau_{k t}-\tilde{\delta} K_{m t} \tau_{k t}-T_{t}
$$

where the upper case variables $H_{m t}$ and $K_{m t}$ are aggregate (or per capita) values of the corresponding lower case variables. Furthermore, we assume that government consumption is a stochastic process given by

$$
c_{g t}=\alpha_{t} Y_{t}
$$

where $\alpha_{t}$ is a random variable and $Y_{t}$ is aggregate market output. We treat the transfer $T_{t}$ as a residual that takes on whatever value that is necessary to satisfy the government

3 This decomposition is simply an accounting identity; in one period, the household chooses investment in total capital, and next period it allocates total capital to either market or nonmarket uses. Note that although we allow capital to move freely across sectors, it is rare that much capital is actually moved in equilibrium, since households typically want to add to both stocks to at least keep pace with depreciation and growth. 
budget constraint at each point in time, given $\alpha_{t}, \tau_{h t}$, and $\tau_{k t}{ }^{4}$ Notice that there is no tax on nonmarket capital. In the United States, residential capital is subject to a property tax, but this tax as well as interest payments on home mortgages are deductible against income taxes. We assume here that the net effect is approximately zero. Taxes on home capital are considered explicitly in Section VI.

Next we describe the technology in the market sector. There is a constant returns to scale technology described by

$$
Y_{t}=f\left(K_{m t}, H_{m t} \mu^{t} e^{s_{m t}}\right)=\left\{a_{4} K_{m t}^{b_{4}}+\left(1-a_{4}\right)\left(H_{m t} \mu^{t} e^{s_{m t}}\right)^{b_{4}}\right\}^{\frac{1}{b_{4}}},
$$

M where $\mu$ is the trend growth rate (which is the same as in the household production function) and $s_{m t}$ is a technology shock. With constant returns, the number of firms is not determinate, and so we normalize this number to one. At each date, the firm hires labor and capital in the market (taking $w_{t}$ and $r_{t}$ as given) to maximize instantaneous profit,

$$
\Pi_{t}=Y_{t}-w_{t} H_{m t}-r_{t} K_{m t}
$$

Maximization implies factor prices equal marginal products; hence, $\Pi=0$ in equilibrium, by the constant returns assumption.

The final aspect of the environment to consider is the stochastic structure. At this point we present a general specification that will be restricted in a later section. The vector of exogenous stochastic variables at $t$ is given by $z_{t}=\left(\alpha_{t}, s_{m t}, s_{n t}, \tau_{k t}, \tau_{h t}\right)$. Then we write

$$
\gamma(L) z_{t+1}=\gamma_{0}+\gamma_{\epsilon} \epsilon_{t}
$$

as a VAR representation of this process, where $L$ denotes the lag operator, $\gamma(L)=I-$ $\gamma_{1} L \ldots-\gamma_{q} L^{q}$, and $\epsilon_{t}$ is a vector with $E \epsilon_{t}=0$ and $E \epsilon_{t} \epsilon_{t}^{\prime}=I$. Let $Z_{t}=\left(z_{t}, z_{t-1}, \ldots, z_{t-q}\right)$. Then $Z_{t}$ contains all of the information that is both available and relevant for forecasting future values of $z_{t}$. We write the law of motion for $Z_{t}$ as $Z_{t+1}=Z\left(Z_{t}, \epsilon_{t}\right)$.

If we were to define and analyze equilibrium for this economy directly, it would entail paths for capital, output, consumption, and investment in each sector which fluctuate

4 We assume that the government balances the budget each period. Although unrealistic, this assumption greatly simplifies the analysis. 
around a trend with growth rate $\mu$, while leisure and hours worked in each sector fluctuate around a constant level. Since it is important for our computational and econometric methods to work with series that are stationary, we transform the economy by replacing $\mathrm{m}$ with 1 , replacing the discount factor $\tilde{\beta}$ with $\beta=\tilde{\beta} \mu^{b(1-\sigma)}$ and replacing the law of motion for capital with $k_{t+1}=(1-\delta) k_{t}+i_{t} / \mu$, where $\delta=1-(1-\tilde{\delta}) / \mu$. In what follows, we treat the transformed economy as the fundamental unit of analysis, since it generates stationary outcomes. The behavior of capital, output, consumption, and investment in the original model can be obtained from the same series for the transformed economy simply by adding geometric growth at rate $\mu$.

We now describe a recursive competitive equilibrium for the transformed economy. There are two aggregate state variables, $K_{t}$ and $Z_{t}$, and one individual state variable, $k_{t}$. The individual household chooses a decision vector $d_{t}=\left(h_{m t}, h_{n t}, k_{m t}, k_{n t}, i_{t}\right)$, taking as given the aggregate decision vector as a function of the aggregate state, $D_{t}=D\left(K_{t}, Z_{t}\right)$, where $D_{t}=\left(H_{m t}, H_{n t}, K_{m t}, K_{n t}, I_{t}\right)$. The individual also takes as given the laws of motion $Z_{t+1}=Z\left(Z_{t}, \epsilon_{t}\right), K_{t+1}=K_{t}(1-\delta)+I_{t} / \mu$, and $k_{t+1}=k_{t}(1-\delta)+i_{t} / \mu$, plus the initial condition $\left(k_{0}, K_{0}, Z_{0}\right)$. Finally, it takes as given the market wage, rental rate, government consumption, and lump sum transfer as functions of the aggregate state: $w_{t}=w\left(K_{t}, Z_{t}\right)$, $r_{t}=r\left(K_{t}, Z_{t}\right), c_{g t}=G\left(K_{t}, Z_{t}\right)$, and $T_{t}=T\left(K_{t}, Z_{t}\right)$. Then the household's problem is a well-posed dynamic program. Bellman's equation is

$$
V\left(k_{t}, K_{t}, Z_{t}\right)=\max _{d_{t}}\left\{U\left(c_{m t}, c_{n t}, c_{g t}, h_{m t}, h_{n t}\right)+\beta E V\left(k_{t+1}, K_{t+1}, Z_{t+1}\right)\right\}
$$

where the maximization is subject to $k_{m t}+k_{n t}=k_{t}$, the home production constraint $(2.8)$, and the budget constraint (2.10).

The solution to the maximization problem in (2.16) yields a stationary decision rule for the household, $d_{t}=d\left(k_{t}, K_{t}, Z_{t}\right)$. This determines an aggregate decision rule, $D_{t}=$ $D\left(K_{t}, Z_{t}\right)$, which in equilibrium must be consistent with what the individual takes as given. Also, we can use the necessary and sufficient conditions for the firm's problem,

$$
\begin{aligned}
r_{t} & =f_{k}\left(K_{m t}, H_{m t} e^{s_{m t}}\right), \\
w_{t} & =f_{h}\left(K_{m t}, H_{m t} e^{s_{m t}}\right),
\end{aligned}
$$


to determine wage and rental rates as functions of $\left(K_{t}, Z_{t}\right)$, which must be consistent with what the individual takes as given. Finally, we can use

$$
\begin{aligned}
c_{g t} & =\alpha_{t} Y_{t}, \\
T_{t} & =H_{m t} w_{t} \tau_{h t}+K_{m t} r_{t} \tau_{k t}-\tilde{\delta} K_{m t} \tau_{k t}-c_{g t},
\end{aligned}
$$

to determine fiscal policy as functions of $\left(K_{t}, Z_{t}\right)$, which must be consistent with what the individual takes as given.

These considerations lead us to formally define an equilibrium for our economy as follows:

Definition: A recursive competitive equilibrium is given by a household value function $V(k, K, Z)$ and decision rule $d(k, K, Z)$, an aggregate decision rule $D(K, Z)$, wage and rental rate functions $w=w(K, Z)$ and $r=r(K, Z)$, and policy functions $G(K, Z)$ and $T(K, Z)$, satisfying:

(a) the dynamic programming problem (2.16);

(b) the profit maximization conditions (2.17) and (2.18);

(c) the fiscal policy equations (2.19) and (2.20);

(d) the consistency requirement $\mathrm{D}(\mathrm{K}, \mathrm{Z})=\mathrm{d}(\mathrm{K}, \mathrm{K}, \mathrm{Z})$.

\section{Estimation Procedure and Data}

We use the procedure described in McGrattan (1992) to solve and estimate the model. We refer the reader to that paper for details, and provide only a brief overview here.

First, we use a deterministic version of the model, in which $\epsilon_{t} \equiv 0$, to find the nonstochastic steady state. Then we substitute the individual household's home production function and its budget constraint into its objective function, and replace wages, rental rates and fiscal variables using conditions (2.17)-(2.20), in order to write the household's objective function as a function of $\left(k, K, Z, d, K_{m}, H_{m}\right) \cdot{ }^{5}$ Following Kydland and Prescott (1982), we then approximate this function using a second order Taylor series around the

5 Note that we replace wage, rental rate, and fiscal policy variables with functions of aggregate (not individual) values of $K_{m}$ and $H_{m}$. 
nonstochastic steady state values of the arguments. This yields a linear-quadratic version of the dynamic programming problem in (2.16), which generates linear Euler equations and linear decision rules. To find equilibria, we have to equate individual and aggregate variables in the Euler equations and solve for time paths of the variables of interest. ${ }^{6}$

This procedure generates the mapping

$$
x_{t+1}=A x_{t}+\eta_{t}
$$

where $x_{t}=\left(k_{t}, Z_{t}\right)$, and from this and the decision rules we can derive the paths for all of the endogenous variables. The elements of $A$ are nonlinear functions of the preference and technology parameter vector

$$
\Gamma=\left(\beta, b, \sigma, a_{1}, b_{1}, a_{2}, b_{2}, a_{3}, b_{3}, a_{4}, b_{4}, \delta, \mu\right)
$$

and the parameters in law of motion (2.15). The elements in $\eta_{t}$ are linear functions of $\epsilon_{\boldsymbol{t}}$. We allow variables to be measured with error. ${ }^{7}$ This yields a measurement equation

$$
\zeta_{t}=C x_{t}+\omega_{t}
$$

where $\zeta_{t}=\left[k_{t}, k_{n t}, h_{m t}, i_{t}, c_{g t}, y_{t}, \tau_{k t}, \tau_{h t}\right]$ is a vector of observables and $\omega_{t}$ is a vector of measurement errors. We assume that

$$
\omega_{t}=D \omega_{t-1}+\nu_{t}
$$

where $E \nu_{t}=0$ and $E \nu_{t} \nu_{t}^{\prime}=\Omega$.

As in Harvey (1981) we specify our empirical model in state space form:

$$
\begin{aligned}
x_{t+1} & =A x_{t}+\eta_{t} \\
\bar{\zeta}_{t} & =\bar{C} x_{t}+\bar{\nu}_{t} .
\end{aligned}
$$

6 Because our equilibria do not solve a planning problem, it is not obvious ex ante that the model generates existence or local uniqueness. However, our estimated parameter values imply that the relevant stability conditions that generate a unique equilibrium are satisfied.

7 Given the large differences in marginal tax rates across studies, the possibility of measurement error seems particularly important for the tax rate series. 
System (3.5) is obtained by differencing (3.3) so that $\bar{\zeta}_{t}=\zeta_{t+1}-D \zeta_{t}, \bar{C}=C A-D C$, and $\bar{\nu}_{t}=C \eta_{t}+\nu_{t}$. If the disturbances, $\eta_{t}$ and $\bar{\nu}_{t}$, are normal, then estimation involves maximizing the likelihood function

$$
L(\Theta)=-T \ln 2 \pi-.5 T \ln |\Sigma|-.5 \sum_{t=1}^{T} u_{t}^{\prime} \Sigma^{-1} u_{t},
$$

where $u_{t}=\bar{\zeta}_{t}-E\left[\bar{\zeta}_{t} \mid \bar{\zeta}_{t-1}, \ldots\right]$ is the innovation process for $\bar{\zeta}_{t}, \Sigma=E u_{t} u_{t}^{\prime}$, and $\Theta$ includes $\Gamma$ plus the parameters of the processes in (2.15) and (3.4). Harvey (1981) shows how one can construct the innovations by applying a Kalman filter to system (3.5).

We now describe the data. All series are quarterly, for the period 1947-1987, and are in real per capita terms. The series for investment, government consumption, private market consumption, and market output are taken from the National Income and Product Accounts. Investment is defined as fixed investment plus purchases of consumer durables. Private market consumption is defined as the consumption of nondurables and services, excluding the service flow attributed to the housing stock (since we would interpret the latter component as nonmarket rather than market consumption). Market output is defined as the sum of investment, government consumption, and private market consumption (hence, it excludes net exports). Market capital is the net stock of private nonresidential structures and equipment. Nonmarket capital is the net stock of private residential capital and consumer durables. These series are obtained from the Survey of Current Business; they are annual data interpolated to quarterly data. The market hours series is defined as total manhours for all industries and all employees taken from the Bureau of Labor Statistics' Household Survey. This is seasonally adjusted monthly data aggregated to quarterly data. The total hours parameter $\bar{h}$ is set to 1,134 hours per quarter (a little over 12 hours per day), which is the measure of discretionary time we took from Hill (1985).

The tax rates on labor and capital income are constructed using the definitions in Joines (1981); they are annual data interpolated to quarterly data. The Appendix contains the actual series. Sources for these measures are the National Income and Product Accounts and the Statistics of Income series of the Internal Revenue Service. The tax rate on labor corresponds to Joines' definition of MTRL1, and the tax rate on capital to Joines' definition of MTRK1 (excluding property tax revenue). This completes the description of 
our data. Note that we have no data on nonmarket hours or nonmarket output; we can still draw inferences about the parameters of preferences and technology for home produced goods, however, because other observable variables depend on these parameters.

\section{Empirical Results}

In this section we describe the empirical results and discuss some of their implications. We begin with preference and technology parameters. Estimates and standard errors for these are found in Table $1 a^{8}$

The estimates for $a_{1}, b_{1}, \sigma, \delta, \beta$, and $\mu$ are similar to estimates for the model without home production found in McGrattan (1992), and so we discuss these only briefly. The parameter $a_{1}$, which measures the weight on private (versus public) consumption in the household utility function, hit an upper bound of 1 and was therefore constrained during estimation (which means that $b_{1}$ is not identified and can be set arbitrarily). This implies government consumption does not affect the marginal utility of private consumption, as has been imposed in some models (see Christiano and Eichenbaum 1992). The risk aversion parameter, $\sigma$, has a point estimate of 5.27 , but a large standard error. This implies that a log-linear specification for momentary utility would suffice. The estimate for depreciation, $\delta$, is 0.022 with a small standard error, which is consistent with results found elsewhere. The estimate of $\beta$ is 0.991 , although not significantly different from 1 . The estimate of the growth rate, $\mu$, is 1.0054 with a small standard error, which is in the range of sample growth rates for our capital stock, output, and investment series.

As mentioned earlier, a key parameter governing the interaction between household and market activity is $b_{2}$, since the elasticity of substitution between the market and nonmarket consumption goods is $1 /\left(1-b_{2}\right)$. Thus, $b_{2}$ measures the willingness of agents to substitute between the two goods. For example, if $b_{2}=1$ then $c_{m}$ and $c_{n}$ are perfect substitutes, and if $b_{2}=0$ then $c_{p}$ is a Cobb-Douglas function of $c_{m}$ and $c_{n}$ so they are complements. Benhabib, Rogerson, and Wright (1991) argue, under certain assumptions, that adding home production to a model has little or no implication for market variables

8 Tables and figures labeled "a" are derived from estimation of the model with geometric growth assumed for the raw data; tables and figures labeled " $b$ " are derived from estimation after filtering the data in a manner to be described below. 
when $b_{2}=0$. Our point estimate of $b_{2}$ is 0.385 , and is significantly different from 0 . This implies a fairly high willingness to substitute between home and market goods, although less than assumed by Benhabib et. al., who set $b_{2}=0.8$ in their preferred model.

To pursue this further, consider a version of our model where $b_{2}=0, b_{3}=0$, and $\sigma$ $=1$ (that is, $c_{p}$ is a Cobb-Douglas function of $c_{m}$ and $c_{n}, c_{n}$ is a Cobb-Douglas function of $k_{n}$ and $h_{n} e^{s_{n}}$, and $u$ is a $\log$-linear function of $c$ and $\ell$ ). Additionally, suppose that all of the coefficients on $s_{n t}$ or its innovations are set to 0 in the equations for $s_{m t}, \alpha_{t}$, $\tau_{h t}$, and $\tau_{k t}$, which implies that $s_{n t}$ is not relevant for forecasting future values of these variables. In this case, innovations in $s_{n t}$ do not affect any of the variables in equilibrium except $c_{n t}{ }^{9}$ There are 15 parameter restrictions in total. We test the hypothesis that these restrictions hold against the unconstrained alternative. The hypothesis is easily rejected using a likelihood ratio test: the probability that $\chi^{2}(15)$ falls below the computed likelihood ratio test statistic is essentially 1 . We conclude that changes in the home production technology have a significant impact.

The remaining preference parameters in Table 1a are $a_{2}$ and $b$, which measure the weight on market (versus home) consumption and the weight on consumption (versus leisure) in momentary utility. These parameters have implications for the allocation of time between the home and market; in fact, previous studies have used micro data on time use to draw inferences on $a_{2}$ and $b$. For example, based on data described in Juster and Stafford (1991), Greenwood, Rogerson, and Wright (1993) report that market work and home work constitute 33 and 25 percent of discretionary time for a typical U.S. household, and use this to pin down $a_{2}$ and $b$. The mean of our market hours series is about 27 percent of $\bar{h}$. We do not have data on home hours, but the model predicts $h_{n}$ is about 12 percent of $\bar{h}$ on average.

We next consider estimates of the production functions. First, note that $b_{4}$ is not sig-

9 This can be verified as follows. First, we substitute the equilibrium conditions for $w, r$, etc. into the first order conditions from (2.16). We then seek restrictions under which $s_{n}$ does not affect $d=\left(k_{m}\right.$, $k_{n}, h_{m}, h_{n}, i$ ), but only affects $c_{n}$. If $b_{2}=0, s_{n}$ drops out of the equation for $h_{m}$ (because when $c_{p}$ is a Cobb-Douglas function of $c_{m}$ and $c_{n}, c_{n}$ does not affect the marginal rate of substitution between $c_{m}$ and $h_{m}$ ). If $b_{3}=0, s_{n}$ drops out of the equations for $h_{n}, k_{n}$, and $k_{m}$ (because when the home production function is Cobb-Douglas, the desired capital-labor ratios do not depend on $s_{n}$ ). If $\sigma=1, s_{n}$ drops out of the Euler equations for $i$ (because when $u$ is $\log$-linear, $c_{n}$ does not affect the marginal utility of $c_{m}$ ) as long as $s_{n}$ does not matter for the expectation of the future values of $s_{m}$ or the fiscal variables. These are exactly the conditions described in the text. 
nificantly different from 0 , indicating that the market technology is approximately CobbDouglas. On the other hand, consistent with the suggestion of Greenwood and Hercowitz (1991), we find that the home production function is not Cobb-Douglas (that is, $b_{3}$ is not equal to zero). The weight on capital in the market technology, $a_{4}$, is 0.234 with a standard error of 0.120 . This is similar to estimates found by others (Christiano and Eichenbaum 1992, for example) who ignore both household production and taxation. Adding capital income taxation to a model causes the estimate of $a_{4}$ to rise, since capital has to be more productive in order to generate the observed stock when it is subject to taxation (McGrat$\tan 1992$, for example, estimates $a_{4}$ to be 0.4 ). On the other hand, incorporating home production causes the estimate of $a_{4}$ to fall, because a large fraction of observed capital is assumed to be allocated to home production. The net effect of these two considerations is an estimate close to that found by authors who neglect both taxation and household production.

We now turn to the stochastic process for $z_{t}$, which was assumed to have two lags $(q=2)$ for estimation. Estimates and standard errors are given in Figure 1a. If the autoregressive process is completely unrestricted, the estimates of the coefficients on $\alpha_{t}$, $s_{m t}, \tau_{h t}$, and $\tau_{k t}$ in the $s_{n t}$ equation are tiny and insignificantly different from 0 . Therefore, we restricted $s_{n t}$ to depend only on its own lags. This helps identify the parameters in the $s_{n t}$ process. Because we do not have data on home consumption or home hours, this process cannot be identified completely. For example, the mean of the household production technology shock is not identifiable. ${ }^{10}$ Therefore, to avoid singularities in the information matrix, the third element of $\gamma_{0}$ in $(2.15)$ is set to 0 when we search the parameter space for a maximum.

In reporting the standard errors, the variance of the error in the $s_{n t}$ equation, $\operatorname{var}\left(\epsilon_{t}\right)$, is also restricted. Excluding the $(3,3)$ element of $\gamma_{\epsilon}$ before computing standard errors significantly affects the standard errors for $a_{2}, a_{3}$, and several covariances between the error term in the $s_{n t}$ equation and the other error terms. For example, if $\gamma_{\epsilon}(3,3)$ is

10 This can be argued as follows. Start with a parameterization $\bar{\Theta}$. Then consider a $\hat{\Theta}$ that differs from $\bar{\Theta}$ in the parameters of the autoregressive process of $z_{t}$ in such a way that the mean of $s_{n t}$ is changed but the means of $\alpha_{t}, s_{m t}, \tau_{h t}$, and $\tau_{k t}$ are the same. Then the preference parameters $b$ and $a_{2}$ can be perturbed in such a way that $\bar{\Theta}$ and $\hat{\Theta}$ generate the same paths for all of the observable variables. 
included in the parameter vector when standard errors are computed, the standard errors for $a_{2}$ and $a_{3}$ are 0.299 and 0.190 , while the standard errors for the remaining utility and production parameters are similar to those reported in Table 1a. We suspect that these differences indicate that not all of the second moments can be identified without data on $c_{n t}$ and $h_{n t}$. In any case, since the standard errors do not change significantly if we eliminate any other covariances before computing standard errors, we report the case with only $\gamma_{\epsilon}(3,3)$ restricted.

Benhabib, Rogerson, and Wright (1991) argue that an important feature of the model is the correlation between the two technology shocks. This is because a lower correlation indicates more frequent relative productivity differentials between the home and market, and hence agents have greater incentives to move activity between the two sectors. Using the numbers in Figure 1a, we compute the correlation between the market and nonmarket productivity shocks to be -0.18 . This is much lower than the value of $2 / 3$ adopted arbitrarily in Benhabib, Rogerson, and Wright (1991). Therefore, our estimates imply greater incentives to substitute between the sectors. Recall that we also estimate a lower willingness to substitute between home and market goods than assumed in that paper. These two differences have roughly offsetting effects; using our estimates in the model of Benhabib et. al. does not change their results very much.

The results from Figure 1a indicate that the $z_{t}$ process is highly persistent. The estimation procedure attempts to capture low frequency movements in the data either through $\gamma(L)$ or through the measurement error process. Estimates of the measurement error process are shown in Figure 2a (note that the measurement errors on output and government consumption are assumed to be zero, and that only hours of work and the tax rates are assumed to have serially correlated measurement errors). Trends are particularly evident in the tax rate series, where $\tau_{h t}$ increases while $\tau_{k t}$ decreases over our sample. This causes a near unit root estimate of either the labor tax rate process or its measurement error. There is also a trend in $h_{m t}$. The result is that the coefficients of $D$ are high.

Because of these considerations, we also estimated the model using data that was first transformed using the Hodrick - Prescott filter (see Prescott 1986), thereby eliminating low frequencies. We tried this not only because of trends in the market hours and tax 
rate series, but also because the theoretical model implies that all series that grow must grow at the same geometric rate. Although this may be correct from some very long run perspective, the growth rates do not match perfectly in our relatively short sample. The filtered case provides a check on the robustness of our utility and production function parameter estimates, in the sense that we can see if they are sensitive to the low frequency properties of the data.

Table $1 \mathrm{~b}$ and Figures $1 \mathrm{~b}$ and $2 \mathrm{~b}$ report the results for this case. Notice that the utility and production function parameters are very similar to those in Table 1a: the differences in point estimates are less than one standard deviation. The main differences between the filtered and unfiltered cases are the estimates of the autoregressive process and the measurement error equations. In particular, after filtering low frequencies in the data we do not have difficulties with near unit roots. Another difference is that the implied correlation between the home and market technology shocks is -0.926 . This implies that households are faced with very frequent relative productivity differentials and hence large incentives to substitute between the home and market.

\section{Cyclical Implications}

Tables $2 \mathrm{a}$ and $2 \mathrm{~b}$ report the standard deviations and correlations with output for several variables, both for the model and the data. Table $2 \mathrm{a}$ uses estimates of the model with geometric growth estimated on the raw data, and Table $2 \mathrm{~b}$ uses the estimates obtained using the Hodrick - Prescott filtered data. Both the model and data series are logged before computing the standard deviations, so these statistics are in percentage terms. The column headed $C \hat{x}$ indicates that $C E\left[x_{t} \mid \bar{\zeta}_{t-1}, \bar{\zeta}_{t-2}, \ldots, \bar{\zeta}_{1}, x_{1}\right]$ is used to obtain the model's predictions, where $x_{1}$ is an estimate of the initial state.

Consider Table 2a, which compares the model and the data in the case of geometric growth. We see that output $y$ and the three capital stock variables, $k_{m}, k_{n}$, and $k$, match extremely well. The match is not quite as good for investment $i$ and market consumption $c_{m}$ : the former is a little too volatile and the latter is a little too smooth in the model, as compared to the data. Market hours in the model are too volatile and too procyclical. The disaggregated investment series $i_{m}$ and $i_{n}$ fluctuate too much; but both are procyclical 
in the model, as they are in the data (Greenwood and Hercowitz 1991 argue that is an important feature). In terms of the fiscal variables, $c_{g}$ matches very well, but $\tau_{h}$ and $\tau_{k}$ do not fluctuate enough in the model. One factor to consider is that some series, especially hours and investment, are highly persistent even after geometric detrending, and estimation may be fitting these features of the data at the cost of fitting higher frequencies. ${ }^{11}$

Now consider Table $2 \mathrm{~b}$, which compares the model and data in the case where estimation uses Hodrick - Prescott filtered data. Again, $y, k_{m}, k_{n}$, and $k$ all match very well in terms of standard deviations, although the capital stocks do not do quite as well as in the previous case in terms of correlations with output. In this case, however, $i$ and $c_{m}$ match very well. In the model, $h_{m}$ is now too smooth, while in the previous case it was too volatile; these results suggest that one has to be careful with statements such as "the model predicts the volatility of hours is too high" or "too low," since their veracity can depend on how one measures volatility. As in the previous case, $i_{m}$ and $i_{n}$ are too volatile in the model, and now $i_{n}$ is not correlated with output. Finally, in this case $c_{g}$ and $\tau_{h}$ match pretty well, $\tau_{k}$ less so.

Overall, we would say that the model does about as well as a typical real business cycle model in matching the set of second moments on which real business cycle theorists tend to concentrate. One might think that this was to be expected. However, our estimation procedure is designed to fit all aspects of the data, including correlations and frequencies other than those summarized by the narrow set of statistics in Tables $2 \mathrm{a}$ and $2 \mathrm{~b}$. Hence, it was not obvious ex ante how well the maximum likelihood estimates would be able to capture these features of the data.

\section{Fiscal Policy Experiments}

In this section, we analyze the effects of three fiscal experiments: eliminating all tax distortions by setting both the labor and capital tax rates to zero; reducing the capital

11 Although not reported, first moments all match very well, except for the tax rates on capital income: the data has an average value of 0.57 , while the model predicts 0.7 . One possibility is that government policy generates disincentives to investment in market capital, through things like regulation, that are not picked up by our sample measure of the capital income tax rate. Another possibility is that there is really more capital in the market than measured by our series (for example, organizational capital). In any case, the model has trouble reconciling the observed market capital stock with our capital tax series. 
income tax rate to zero while increasing the labor income tax rate to keep revenue constant; and introducing a tax on nonmarket capital. We also try to point out how our predictions differ from those generated by a similar model without household production.

For the first two policy experiments, Table 3 reports percent changes in output, consumption, investment, hours worked, and capital in both the home and market sectors, plus a variable $\Delta$ that measures the welfare consequences in terms of market consumption. It is interpreted as follows: if, for example, $\Delta=0.01$, then agents would be equally well off after the policy change if their market consumption were reduced by 1 percent of its new steady state value, all else being the same. Percentage changes are relative to a base case with $\tau_{k}=0.57$ and $\tau_{h}=0.23$ (the sample averages in the data). The first experiment sets $\tau_{k}=\tau_{h}=0$, and the second sets $\tau_{k}=0$ and sets $\tau_{h}$ at the indicated level in order to keep revenue constant. Government consumption is the same in each case, and is set to balance the budget in the base case; in the experiment with $\tau_{k}=\tau_{h}=0, c_{g}$ is financed exclusively via lump sum taxation.

Based on our parameter estimates, the effect of eliminating distorting taxation altogether is quite sizable: output increases by 43 percent, market consumption increases by 47 percent, market investment increases by 83 percent, market hours increase by 22 percent, and the stock of market capital more than doubles. In the home sector, consumption decreases by 1.4 percent, hours decrease by 20 percent, and capital increases by 34 percent. Hence, there is a shift of labor from home to market production, but an increase in capital in both sectors. In terms of welfare, the policy change is worth 22 percent of market consumption. A model that ignores the home sector has very different predictions. For example, as shown in the second column of the table, the model in McGrattan (1992) predicts for the same policy change an increase in both output and market consumption of 58 percent and an increase in total capital of 133 percent, much larger than in our model. The response of market hours is the same for the two models; but, because home hours change in our model, the implications for leisure are different. In terms of welfare, the policy is worth 27.8 percent of market consumption in the McGrattan model.

Next consider the effect of eliminating the capital tax and raising the labor tax to keep revenue constant. Given our estimates, the labor tax rate would have to increase 
from 0.23 to 0.31 percent. This is accompanied by a 14 percent increase in output, a 6 percent increase in market consumption, a 45 percent increase in investment, a 77 percent increase in the market capital stock, and a 3 percent decrease in market hours. The welfare gain is 10.6 percent of market consumption. In contrast, the model without home production predicts that eliminating capital taxation requires increasing $\tau_{h}$ to 0.36 to keep revenue constant, that output increases by 21 percent, market consumption increases by 8.6 percent, investment and the capital stock both increase by 79 percent, and market hours fall by 6.2 percent. The welfare gain is 14.7 percent of consumption. Once again, there are big differences between the models with and without home production.

For the final experiment, we consider adding a tax on household capital (an experiment that cannot be conducted in a model without home production, of course). We replace the individual budget constraint with

$$
c_{m}+i \leq\left(1-\tau_{h}\right) w h_{m}+\left(1-\tau_{k}\right) r k_{m}+\tilde{\delta} \tau_{k} k_{m}+T-\tau_{p} k_{n}
$$

where $\tau_{p}$ is a "property" tax. Jorgenson and Yun (1991) argue that a value of $\tau_{p}=0.01$ is realistic when it is interpreted as a residential property tax. Table 4 reports percent changes for output, consumption, investment, hours worked, and capital in both the home and market sectors, plus our welfare measure for economies with $\tau_{p}=0.01,0.02$, and 0.03 relative to a base case with $\tau_{p}=0$. In all cases, we set $\tau_{h}=0.23$ and $\tau_{k}=0.57$.

With the exception of market consumption, all variables are lower when $\tau_{p}$ is positive than in the base case. Output produced at home falls 11 percent when $\tau_{p}$ is increased to 0.01 . At $\tau_{p}=0.03$, home production falls 25 percent. Not surprisingly, there is a significant decrease in home capital, which is the factor being taxed. Hours in home production fall but only slightly. Because home capital is produced in the market, market production also falls when $\tau_{p}$ is increased. Notice that inputs and outputs in the market fall by the same percentages. This follows from the fact that the property tax does not affect the market capital/labor ratio. The tax leads to a large fall in investment, and households increase their market consumption. The subsidy to market consumption needed to leave households indifferent between having $\tau_{p}>0$ and $\tau_{p}=0$ is given in the last row of Table 4. For $\tau_{p}=0.01$, the subsidy required is 3.3 percent of market consumption. At $\tau_{p}=0.03$, the subsidy required is 9.1 percent. 


\section{Conclusion}

In this paper, we evaluate the importance of home production in models of aggregate economic activity by obtaining maximum likelihood estimates of a stochastic growth model with an explicit household sector. The parameters that are most important for the hypothesis that household production affects market activity are the elasticity of substitution between output of the two sectors, the correlation between shocks to the home and market technologies, and parameters of the home production function. Our estimates suggest that

there is a significant elasticity of substitution between home and market goods. Estimated correlations of the home and market technology shocks suggest that there are frequent opportunities for such substitution.

Furthermore, we can reject restrictions on the model that imply market activity is not affected by changes in the home production technology. We also examine how well the estimated model accounts for the standard set of moments on which real business cycle theorists like to focus, and use the model to study the effects of fiscal policy changes. We find that including home production significantly affects the model's predictions along certain dimensions. There are a variety of other issues for which the addition of an explicit home production sector may make a difference. In such cases, the model and the parameter estimates in this paper may prove useful. 


\section{References}

[1] Altug, Sumru (1989), "Time-to-Build and Aggregate Fluctuations: Some New Evidence," International Economic Review, 30: 889-920.

[2] Becker, Gary S. (1988), "Family Economics and Macro Behavior," American Economic Review, 78: 1-13.

[3] Benhabib, Jess, Richard Rogerson, and Randall Wright (1991), "Homework in Macroeconomics: Household Production and Aggregate Fluctuations," Journal of Political Economy, 99: 1166-1187.

[4] Christiano, Lawrence J. (1988), "Why Does Inventory Investment Fluctuate So Much?" Journal of Monetary Economics, 21: 247-280.

[5] Christiano, Lawrence J. and Martin Eichenbaum (1992), "Current Real Business Cycle Theories and Aggregate Labor Market Fluctuations," American Economic Review, 82: $430-450$.

[6] Greenwood, Jeremy and Zvi Hercowitz (1991), "The Allocation of Capital and Time over the Business Cycle," Journal of Political Economy, 99: 1188-1214.

[7] Greenwood, Jeremy, Richard Rogerson and Randall Wright (1993), "Household Production in Real Business Cycle Theory," in Frontiers of Business Cycle Research, ed. T.F. Cooley, Princeton: Princeton University Press.

[8] Harvey, Andrew C. (1981), Time Series Models, New York: Wiley and Sons.

[9] Hill, M. (1985), "Patterns of Time Use," in Time, Goods and Well-Being, eds. F.T. Juster and F.P. Stafford, Ann Arbour: University of Michigan Press.

[10] Joines, Douglas H. (1981), "Estimates of Effective Marginal Tax Rates on Factor Incomes," Journal of Business, 54:191-226.

[11] Juster, F. Thomas and Frank P. Stafford (1991), "The Allocation of Time: Empirical Findings, Behavioral Models, and Problems of Measurement," Journal of Economic Literature, 29: 471-522.

[12] Jorgenson, Dale W. and Kun-Young Yun (1991), Tax Reform and the Cost of Capital, Oxford: Clarendon Press.

[13] Kydland, Finn E. and Edward C. Prescott (1982), "Time to Build and Aggregate 
Fluctuations," Econometrica, 50: 1345-1370.

[14] McGrattan, Ellen R. (1992), "The Macroeconomic Effects of Distortionary Taxation," Journal of Monetary Economics, forthcoming.

[15] Prescott, Edward C. (1986), "Theory Ahead of Business Cycle Measurement," CarnegieRochester Conference on Public Policy, 25: 11-44.

[16] Stokey, Nancy L. and Sergio Rebelo (1993), "Growth Effects of Flat-rate taxes," mimeo, Northwestern University.

[17] Rios-Rull, Jose-Victor (1993), "Working in the Market, Working at Home, and the Acquisition of Skills," American Economic Review, 83: 893-907. 


\section{Appendix A}

The effective tax rates for labor and capital used to estimate the model are given in Table A. The data sources for these series are Statistics of Income, Individual Income Tax Returns (Sources of Income and Taxable Income, all returns) and Social Security Bulletin (Tables 2a, 4b). The rates are constructed using the definitions of Joines (1981), series MTRK1, MTRL1. One important difference between $\tau_{k, t}$ of Table A and MTRK1 in Joines is the treatment of property taxes. MTRK1 is the sum of a proportional tax on income that is not specific to capital or labor, a proportional tax on income that is specific to capital, and a nonproportional tax on income that is specific to capital. The proportional tax on income that is specific to capital is simply tax receipts from capital divided by income from capital. We exclude property taxes from both tax receipts and Joines' measure of income which includes indirect business taxes.

\begin{tabular}{|c|c|c|c|c|c|c|c|c|}
\hline$t$ & $\tau_{k t}$ & $\tau_{h t}$ & $t$ & $\tau_{k t}$ & $\tau_{h t}$ & $t$ & $\tau_{k t}$ & $\tau_{h t}$ \\
\hline 1947 & 62.8 & 20.0 & 1961 & 61.6 & 21.9 & 1975 & 55.8 & 24.9 \\
\hline 1948 & 54.8 & 17.2 & 1962 & 57.3 & 22.0 & 1976 & 56.9 & 25.0 \\
\hline 1949 & 52.4 & 17.2 & 1963 & 57.3 & 22.4 & 1977 & 54.3 & 25.6 \\
\hline 1950 & 64.2 & 18.3 & 1964 & 55.2 & 21.2 & 1978 & 53.4 & 25.6 \\
\hline 1951 & 66.9 & 19.8 & 1965 & 53.4 & 20.5 & 1979 & 53.3 & 26.3 \\
\hline 1952 & 63.9 & 20.8 & 1966 & 53.4 & 21.1 & 1980 & 54.5 & 27.9 \\
\hline 1953 & 64.4 & 21.0 & 1967 & 54.4 & 21.4 & 1981 & 50.2 & 28.4 \\
\hline 1954 & 61.1 & 19.4 & 1968 & 59.8 & 23.0 & 1982 & 49.6 & 27.4 \\
\hline 1955 & 59.8 & 19.6 & 1969 & 60.4 & 24.1 & 1983 & 47.5 & 26.6 \\
\hline 1956 & 61.5 & 20.2 & 1970 & 55.4 & 24.6 & 1984 & 46.6 & 26.1 \\
\hline 1957 & 60.4 & 20.9 & 1971 & 57.7 & 23.3 & 1985 & 47.8 & 26.1 \\
\hline 1958 & 60.7 & 20.7 & 1972 & 57.3 & 23.5 & 1986 & 52.9 & 25.9 \\
\hline 1959 & 60.4 & 21.3 & 1973 & 57.0 & 24.0 & 1987 & 53.8 & 25.7 \\
\hline 1960 & 60.6 & 21.6 & 1974 & 59.3 & 25.1 & & & \\
\hline
\end{tabular}

Table A. Effective Tax Rates for Capital and Labor 


\begin{tabular}{|c|c|}
\hline Function & Parameter Estimates \\
\hline$u(c, \ell)=\frac{\left(c^{b} \ell^{1-b}\right)^{1-\sigma}}{1-\sigma}$ & $b=\underset{(.121)}{.448,} \sigma=\underset{(6.84)}{5.27}$ \\
\hline$c=\left\{a_{1} c_{p}^{b_{1}}+\left(1-a_{1}\right) c_{g}^{b_{1}}\right\}^{\frac{1}{b_{1}}}$ & $a_{1}=1.0, \quad b_{1}=0$ \\
\hline$c_{p}=\left\{a_{2} c_{m}^{b_{2}}+\left(1-a_{2}\right) c_{n}^{b_{2}}\right\}^{\frac{1}{b_{2}}}$ & $a_{2}=\underset{(.0591)}{.485}, b_{2}=.385$ \\
\hline$c_{n}=\left\{a_{3} k_{n}^{b_{3}}+\left(1-a_{3}\right)\left(e^{s_{n}} h_{n}\right)^{b_{3}}\right\}^{\frac{1}{b_{3}}}$ & $a_{3}=\underset{(.0810)}{.210}, b_{3}=.200$ \\
\hline$y=\left\{a_{4} k_{m}^{b_{4}}+\left(1-a_{4}\right)\left(e^{s_{m}} h_{m}\right)^{b_{4}}\right\}^{\frac{1}{b_{4}}}$ & $a_{4}=\underset{(.120)}{.234}, b_{4}=\underset{(.381)}{.0525}$ \\
\hline$\tilde{k}=(1-\delta) k+i / \mu$ & $\delta=\underset{(.000311)}{.0223, \mu}=\underset{(.000433)}{1.0054}$ \\
\hline$\beta$ & $\beta=\underset{(.0150)}{.991}$ \\
\hline
\end{tabular}

Table 1a. Parameters of Preferences and Technology (Geometric Trend)

\begin{tabular}{|c|c|}
\hline Function & Parameter Estimates \\
\hline$u(c, \ell)=\frac{\left(c^{b} \ell^{1-b}\right)^{1-\sigma}}{1-\sigma}$ & $b=\underset{(.158)}{.427}, \sigma=\underset{(7.62)}{5.29}$ \\
\hline$c=\left\{a_{1} c_{p}^{b_{1}}+\left(1-a_{1}\right) c_{g}^{b_{1}}\right\}^{\frac{1}{b_{1}}}$ & $a_{1}=1.0, \quad b_{1}=0$ \\
\hline$c_{p}=\left\{a_{2} c_{m}^{b_{2}}+\left(1-a_{2}\right) c_{n}^{b_{2}}\right\}^{\frac{1}{b_{2}}}$ & $a_{2}=\underset{(.118)}{.477}, b_{2}=\underset{(.184)}{.285}$ \\
\hline$c_{n}=\left\{a_{3} k_{n}^{b_{3}}+\left(1-a_{3}\right)\left(e^{s_{n}} h_{n}\right)^{b_{3}}\right\}^{\frac{1}{b_{3}}}$ & $a_{3}=\underset{(.0704)}{.158,} b_{3}=.247$ \\
\hline$y=\left\{a_{4} k_{m}^{b_{4}}+\left(1-a_{4}\right)\left(e^{s_{m}} h_{m}\right)^{b_{4}}\right\}^{\frac{1}{b_{4}}}$ & $a_{4}=\underset{(.114)}{.228}, b_{4}=\underset{(.200)}{.106}$ \\
\hline$\tilde{k}=(1-\delta) k+i / \mu$ & $\delta=\underset{(.000114)}{.0224, \mu}=1.0$ \\
\hline$\beta$ & $\beta=\underset{(.00435)}{.989}$ \\
\hline
\end{tabular}

Table 1b. Parameters of Preferences and Technology (Data Filtered) 


$$
\begin{aligned}
& z_{t+1}=\left(\begin{array}{lllll}
\alpha & s_{m} & s_{n} & \tau_{k} & \tau_{h}
\end{array}\right)_{t+1}^{\prime}=\left(\begin{array}{ccccc}
-.000542 & .108 & 0 & .0455 & .0193 \\
(.0358) & (.0895) & & (.0145) & (.0157)
\end{array}\right) \\
& +\left(\begin{array}{ccccc}
1.56 & .0151 & -.00336 & -.0917 & .514 \\
(.115) & (.0512) & (.00642) & (.307) & (.311) \\
.356 & .880 & -.0146 & .159 & -.0817 \\
(.186) & (.0952) & (.0163) & (.596) & (.605) \\
0 & 0 & .954 & 0 & 0 \\
& & (.0787) & & \\
.0182 & -.0505 & .0108 & 1.68 & .106 \\
(.0584) & (.0526) & (.00605) & (.129) & (.116) \\
-.0754 & -.0252 & .00338 & .0432 & 1.70 \\
(.0347) & (.0201) & (.00253) & (.109) & (.104)
\end{array}\right) z_{t} \\
& +\left(\begin{array}{ccccc}
-.598 & -.00890 & .00431 & .0975 & -.540 \\
(.113) & (.0514) & (.00674) & (.284) & (.324) \\
-.202 & .0560 & -.000639 & -.136 & -0.101 \\
(.170) & (.102) & (.0168) & (.573) & (.635) \\
0 & 0 & .00558 & 0 & 0 \\
& & (.0700) & & \\
.00663 & .0435 & -.0105 & -.714 & -.166 \\
(.0570) & (.0516) & (.00621) & (.126) & (.124) \\
.0889 & .0173 & -.00538 & -.0388 & -.740 \\
(.0305) & (.0211) & (.00246) & (.104) & (.112)
\end{array}\right) z_{t-1} \\
& +\left(\begin{array}{ccccc}
.00407 & 0 & 0 & 0 & 0 \\
(.000591) & & & & \\
.00210 & .0113 & 0 & 0 & 0 \\
(.00120) & (.00222) & & & \\
.0396 & -.0422 & .0763 & 0 & 0 \\
(.0100) & (.0188) & & & \\
-.000150 & .00125 & -.00101 & .000877 & 0 \\
(.000407) & (.000711) & (.000474) & (.000286) & \\
-.0000204 & .000446 & -.000367 & .000303 & .00119 \\
(.000206) & (.000261) & (.000160) & (.000358) & (.000217)
\end{array}\right) \epsilon_{t}
\end{aligned}
$$

Figure 1a. Vector Autoregression for $\mathbf{z}$ (Geometric Trend)

$$
\begin{aligned}
& \zeta_{t}=\zeta_{t}^{*}+\omega_{t}, \quad \omega_{t}=D \omega_{t-1}+\eta_{t} \\
& D_{i i}=(0,0, .991,0,0,0, .990, .986) \\
& \text { (.0144) (.0123) (.0146) } \\
& \Omega_{i i}=(21.4,39.1,6.75,3253,0,0,4.26 e-5,1 e-7) \\
& \begin{array}{lllll}
(9.15) & (26.8)(.691) & (511) \quad\left(4.49 \times 10^{-6}\right) & \left(2.29 \times 10^{-7}\right)
\end{array}
\end{aligned}
$$

Figure 2a. Measured $(\zeta)$ and Actual Data $\left(\zeta^{*}\right)$ (Geometric Trend) 


$$
\begin{aligned}
& z_{t+1}=\left(\begin{array}{lllll}
\alpha & s_{m} & s_{n} & \tau_{k} & \tau_{h}
\end{array}\right)_{t+1}^{\prime}=\left(\begin{array}{ccccc}
-.0243 & .347 & 0 & .107 & .0603 \\
(.0497) & (.174) & & (.0754) & (.0371)
\end{array}\right) \\
& +\left(\begin{array}{ccccc}
1.35 & .0245 & -.00770 & -.0563 & .557 \\
(.0834) & (.0599) & (.0459) & (.122) & (.399) \\
.366 & .729 & -.0304 & .0545 & .180 \\
(.286) & (.142) & (.159) & (.406) & (.985) \\
0 & 0 & .967 & 0 & 0 \\
& & (.210) & & \\
.0658 & -.0709 & .0190 & 1.49 & .639 \\
(.116) & (.107) & (.0779) & (.196) & (.644) \\
-.0350 & -.0588 & -.0463 & .0171 & 1.56 \\
(.0581) & (.0466) & (.0210) & (.0991) & (.225)
\end{array}\right) z_{t} \\
& +\left(\begin{array}{ccccc}
-.532 & .00118 & .00714 & -.0188 & -.203 \\
(.0695) & (.0524) & (.0428) & (.138) & (.367) \\
-.0848 & .00496 & -.0238 & .178 & -0.692 \\
(.190) & (.112) & (.161) & (.430) & (.942) \\
0 & 0 & .0254 & 0 & 0 \\
& & (.206) & & \\
.0580 & .0473 & -.0294 & -.634 & -.708 \\
(.122) & (.103) & (.0724) & (.200) & (.542) \\
.0810 & .0161 & .0357 & .0168 & -.683 \\
(.0625) & (.0372) & (.0190) & (.0948) & (.220)
\end{array}\right) z_{t-1} \\
& +\left(\begin{array}{ccccc}
.00265 & 0 & 0 & 0 & 0 \\
(.000322) & & & & \\
-.000121 & .00824 & 0 & 0 & 0 \\
(.000952) & (.00285) & & & \\
.00184 & -.00535 & .0177 & 0 & 0 \\
(.00375) & (.00953) & & & \\
.000401 & .00145 & -.000848 & .00224 & 0 \\
(.000564) & (.000493) & (.000936) & (.000670) & \\
.000167 & .0000712 & -.000282 & .000629 & .00000353 \\
(.000271) & (.000321) & (.000405) & (.000491) & (.0682)
\end{array}\right) \epsilon_{t}
\end{aligned}
$$

Figure $1 b$. Vector Autoregression for $\mathbf{z}$ (Data Filtered)

$$
\begin{aligned}
& \zeta_{t}=\zeta_{t}^{*}+\omega_{t}, \quad \omega_{t}=D \omega_{t-1}+\eta_{t} \\
& D_{i i}=(.938, .901, .648, .782, .790, .773, .832 .501) \\
& \text { (.0747)(.0929) (.0478) (.104) (.203) (.292) (.303) (.187) } \\
& \Omega_{i i}=\left(1106,674,4.36,19.7,11.9,30.1,1.63 \times 10^{-5}, 1.13 \times 10^{-7}\right)
\end{aligned}
$$

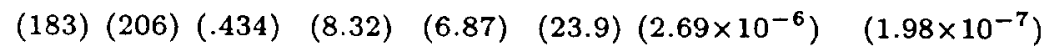

Figure 2b. Measured $(\zeta)$ and Actual Data $\left(\zeta^{*}\right)$ (Data Filtered) 


\begin{tabular}{ccccc}
\hline \multirow{2}{*}{ Series $(z)$} & \multicolumn{2}{c}{ Data $(\zeta)$} & \multicolumn{2}{c}{ Model $(C \hat{x})$} \\
\cline { 2 - 5 } & $\operatorname{std}(\ln (z))$ & $\operatorname{corr}(z, y)$ & $\operatorname{std}(\ln (z))$ & $\operatorname{corr}(z, y)$ \\
\hline$k$ & 4.08 & 0.67 & 4.07 & 0.66 \\
$k_{n}$ & 4.94 & 0.62 & 4.94 & 0.61 \\
$h_{m}$ & 3.09 & 0.32 & 4.04 & 0.98 \\
$i$ & 7.18 & 0.44 & 9.04 & 0.74 \\
$c_{g}$ & 20.23 & 0.62 & 20.17 & 0.61 \\
$y$ & 9.24 & 1.00 & 9.21 & 1.00 \\
$t_{k}$ & 8.24 & 0.76 & 3.85 & 0.71 \\
$t_{h}$ & 12.76 & -0.72 & 5.69 & -0.70 \\
$k_{m}$ & 3.38 & 0.69 & 3.34 & 0.68 \\
$c_{m}$ & 8.23 & 0.91 & 6.89 & 0.82 \\
$i_{m}$ & 7.92 & 0.40 & 13.23 & 0.62 \\
$i_{n}$ & 9.57 & 0.31 & 14.01 & 0.52 \\
\hline
\end{tabular}

Table 2a. Standard Deviations and Correlations for Data and Model (Geometric Growth)

\begin{tabular}{ccccc}
\hline & \multicolumn{2}{c}{ Data $(\zeta)$} & \multicolumn{2}{c}{ Model $(C \hat{x})$} \\
\cline { 2 - 5 } Series $(z)$ & $\operatorname{std}(\ln (z))$ & $\operatorname{corr}(z, y)$ & $\operatorname{std}(\ln (z))$ & $\operatorname{corr}(z, y)$ \\
\hline$k$ & 0.37 & 0.64 & 0.34 & 0.26 \\
$k_{n}$ & 0.53 & 0.63 & 0.53 & 0.34 \\
$h_{m}$ & 1.52 & 0.69 & 0.94 & 0.99 \\
$c_{g}$ & 5.62 & 0.52 & 5.34 & 0.55 \\
$i$ & 5.06 & 0.62 & 4.84 & 0.57 \\
$y$ & 1.94 & 1.00 & 1.94 & 1.00 \\
$t_{k}$ & 3.11 & 0.12 & 1.82 & 0.49 \\
$t_{h}$ & 2.53 & 0.25 & 2.40 & 0.26 \\
$k_{m}$ & 0.35 & 0.45 & 0.34 & -0.01 \\
$c_{m}$ & 1.21 & 0.85 & 1.29 & 0.93 \\
$i_{m}$ & 5.26 & 0.63 & 9.95 & 0.47 \\
$i_{n}$ & 5.75 & 0.63 & 8.52 & 0.00 \\
\hline
\end{tabular}

Table 2b. Standard Deviations and Correlations for Data and Model (Data Filtered) 


\begin{tabular}{ccccc}
\hline & \multicolumn{2}{c}{ (a) Lump-Sum Tax } & \multicolumn{2}{c}{ (b) No Capital Tax } \\
\cline { 2 - 5 } Series & $\begin{array}{c}\text { With } \\
\text { Household Sector }\end{array}$ & $\begin{array}{c}\text { Without } \\
\text { Household Sector }\end{array}$ & $\begin{array}{c}\text { With } \\
\text { Household Sector }\end{array}$ & $\begin{array}{c}\text { Without } \\
\text { Household Sector }\end{array}$ \\
\hline$y$ & 42.7 & 57.8 & 13.7 & 21.3 \\
$c_{m}$ & 46.6 & 56.7 & 6.0 & 8.6 \\
$i$ & 82.9 & 133.0 & 44.6 & 79.1 \\
$k_{m}$ & 123.7 & 133.0 & 77.4 & 79.1 \\
$h_{m}$ & 22.2 & 22.1 & -3.0 & -6.2 \\
$c_{n}$ & -1.4 & & 2.2 & \\
$k_{n}$ & 33.7 & & 5.1 & \\
$h_{n}$ & -19.7 & & 0.4 & \\
$\Delta$ & 22.1 & 27.8 & 10.6 & 14.7 \\
\hline
\end{tabular}

Table 3. Percent changes between case (a) $\tau_{k}=0, \tau_{h}=0$ or case (b) $\tau_{k}=0, \tau_{h}=0.31$ (with household production) $\tau_{h}=0.365$ (without household production) and the base case $\left(\tau_{k}=0.57, \tau_{h}=0.23\right)$.

\begin{tabular}{crcr}
\hline & \multicolumn{3}{c}{ Tax on Residential Capital $\left(\tau_{p}\right)$} \\
\cline { 2 - 4 } Series & 0.01 & 0.02 & 0.03 \\
\hline$y$ & -1.24 & -1.81 & -2.06 \\
$c_{m}$ & 3.08 & 5.31 & 7.03 \\
$i$ & -12.50 & -20.12 & -26.16 \\
$k_{m}$ & -1.24 & -1.81 & -2.06 \\
$h_{m}$ & -1.24 & -1.81 & -2.06 \\
$c_{n}$ & -11.14 & -19.14 & -25.22 \\
$k_{n}$ & -26.06 & -42.17 & -52.99 \\
$h_{n}$ & -0.41 & -0.94 & -1.50 \\
$\Delta$ & 3.32 & 6.37 & 9.08 \\
\hline
\end{tabular}

Table 4. Percent changes between cases with $\tau_{p}>0$ and base case $\left(\tau_{p}=0\right)$. 